\title{
FY2017 Pilot Project Plan for the Nuclear Energy Knowledge and Validation Center Initiative
}

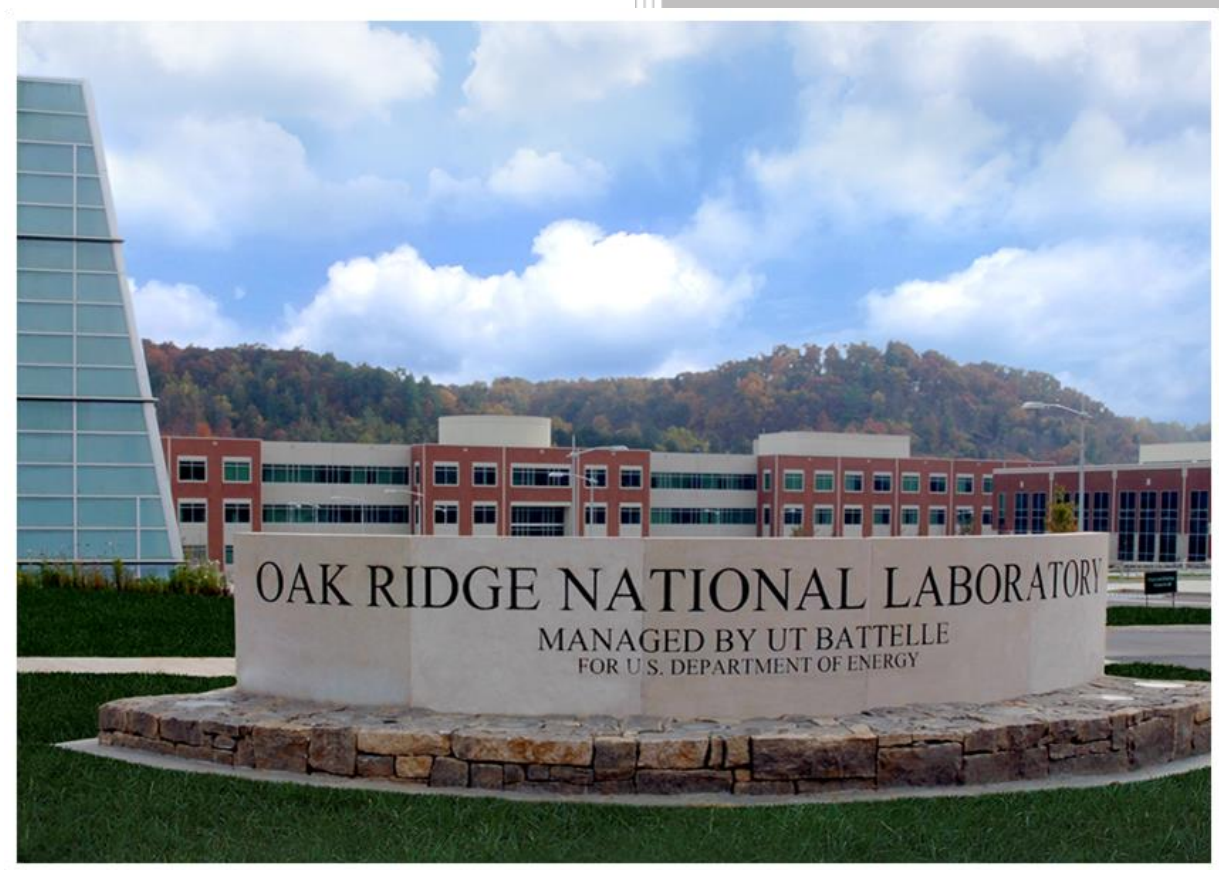

Weiju Ren

October 30, 2016

Approved for public release. Distribution is unlimited. 


\title{
DOCUMENT AVAILABILITY
}

Reports produced after January 1, 1996, are generally available free via US Department of Energy (DOE) SciTech Connect.

Website http://www.osti.gov/scitech/

Reports produced before January 1, 1996, may be purchased by members of the public from the following source:

\author{
National Technical Information Service \\ 5285 Port Royal Road \\ Springfield, VA 22161 \\ Telephone 703-605-6000 (1-800-553-6847) \\ TDD 703-487-4639 \\ Fax 703-605-6900 \\ E-mail info@ntis.gov \\ Website http://www.ntis.gov/help/ordermethods.aspx
}

Reports are available to DOE employees, DOE contractors, Energy Technology Data Exchange representatives, and International Nuclear Information System representatives from the following source:

Office of Scientific and Technical Information

PO Box 62

Oak Ridge, TN 37831

Telephone 865-576-8401

Fax 865-576-5728

E-mail reports@osti.gov

Website http://www.osti.gov/contact.html

This report was prepared as an account of work sponsored by an agency of the United States Government. Neither the United States Government nor any agency thereof, nor any of their employees, makes any warranty, express or implied, or assumes any legal liability or responsibility for the accuracy, completeness, or usefulness of any information, apparatus, product, or process disclosed, or represents that its use would not infringe privately owned rights. Reference herein to any specific commercial product, process, or service by trade name, trademark, manufacturer, or otherwise, does not necessarily constitute or imply its endorsement, recommendation, or favoring by the United States Government or any agency thereof. The views and opinions of authors expressed herein do not necessarily state or reflect those of the United States Government or any agency thereof. 
Nuclear Energy Knowledge and Validation Center Initiative

\title{
FY2017 Pilot Project Plan for the Nuclear Energy Knowledge and Validation Center Initiative
}

\author{
Weiju Ren
}

Date Published: October 30, 2016

\author{
Prepared by \\ OAK RIDGE NATIONAL LABORATORY \\ Oak Ridge, TN 37831-6283 \\ managed by \\ UT-BATTELLE, LLC \\ for the \\ US DEPARTMENT OF ENERGY \\ under contract DE-AC05-00OR22725
}


This page is intentionally left blank 
TABLE OF CONTENTS

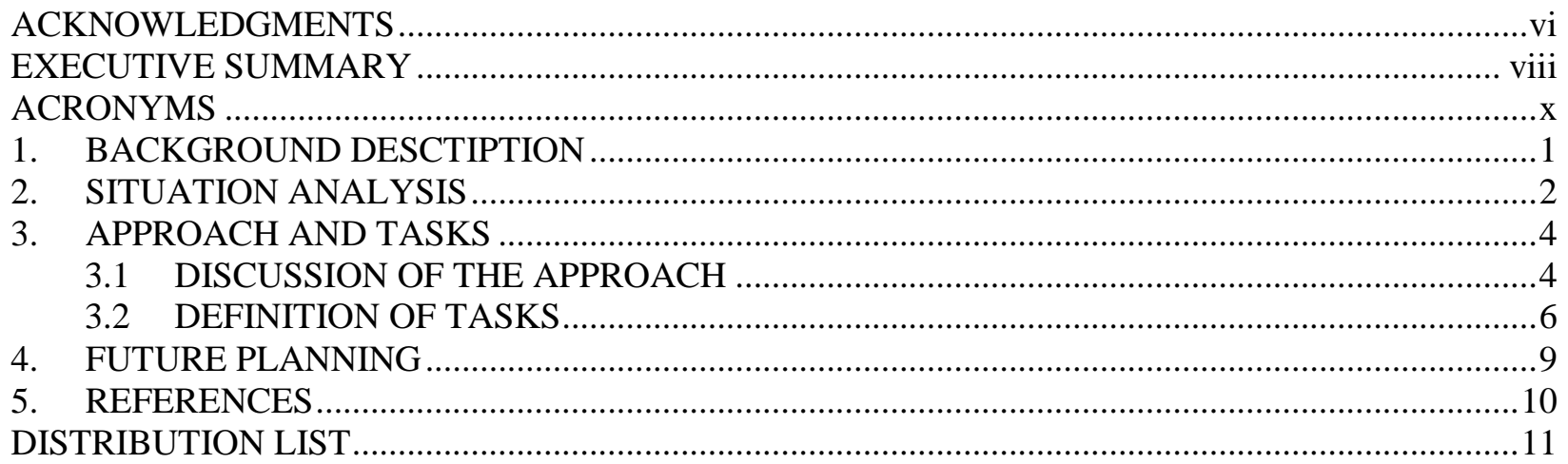




\section{ACKNOWLEDGMENTS}

The author is grateful to Hans Gougar, director of the Nuclear Energy Knowledge and Validation Center, for programmatic direction and financial support; to Charlie Folsom, Cristian Rabiti, J. Phillip Sharpe and Daniel Wachs of the Idaho National Laboratory for meeting with me to discuss the project; to Brad Rearden and Tim Valentine of the Oak Ridge National Laboratory for technical review of this document.

This work is sponsored by the U.S. Department of Energy, Office of Nuclear Energy Science and Technology under contract DE-AC05-00OR22725 with Oak Ridge National Laboratory, managed by UT-Battelle, LLC. 
This page is intentionally left blank 


\section{EXECUTIVE SUMMARY}

To prepare for technical development of computational code validation under the Nuclear Energy Knowledge and Validation Center (NEKVAC) initiative, several meetings were held by a group of experts of the Idaho National Laboratory (INL) and the Oak Ridge National Laboratory (ORNL) to develop requirements of, and formulate a structure for, a transient fuel database through leveraging existing resources. It was concluded in discussions of these meetings that a pilot project is needed to address the most fundamental issues that can generate immediate stimulus to near-future validation developments as well as long-lasting benefits to NEKVAC operation. The present project is proposed based on the consensus of these discussions.

Analysis of common scenarios in code validation indicates that the incapability of acquiring satisfactory validation data is often a showstopper that must first be tackled before any confident validation developments can be carried out. Validation data are usually found scattered in different places most likely with interrelationships among the data not well documented, incomplete with information for some parameters missing, nonexistent, or unrealistic to experimentally generate. Furthermore, with very different technical backgrounds, the modeler, the experimentalist, and the knowledgebase developer that must be involved in validation data development often cannot communicate effectively without a data package template that is representative of the data structure for the information domain of interest to the desired code validation.

This pilot project is proposed to use the legendary TREAT Experiments Database to provide core elements for creating an ideal validation data package. Data gaps and missing data interrelationships will be identified from these core elements. All the identified missing elements will then be filled in with experimental data if available from other existing sources or with dummy data if nonexistent. The resulting hybrid validation data package (composed of experimental and dummy data) will provide a clear and complete instance delineating the structure of the desired validation data and enabling effective communication among the modeler, the experimentalist, and the knowledgebase developer. With a good common understanding of the desired data structure by the three parties of subject matter experts, further existing data hunting will be effectively conducted, new experimental data generation will be realistically pursued, knowledgebase schema will be practically designed; and code validation will be confidently planned.

The hybrid data package will first be uploaded into the Nuclear Energy-Knowledgebase for Advanced Modeling and Simulation (NE-KAMS) along with some expansion of the NE-KAMS structure as needed to establish a common base for communications among the three parties of subject matter experts. The uploaded hybrid data package will also provide a map for creating a complete validation data package of experimental data, and further, facilitate networking scattered existing datasets preserved in different sources for the complete package. The network will allow new experimental data to be generated and preserved in databases at different locations, e.g. NDMAS at INL or VELO at PNNL, for cost and time efficiency. Meanwhile, a duplicate will be uploaded into NE-KAMS for backup and enhanced accessibility.

Completion of this pilot project will establish requirements for a networked transient fuel database, formulate the structure of transient fuel information domain, deliver a tangible framework along with operation protocols for transient fuel validation data accumulation and management, provide a visual instance of a complete validation data package to facilitate future experimental data generation and validation development planning, and retain unique expertise required for long-term NEKVAK development and operation. It will also set a precedent for networking international databases and facilitate planning for collaborating with the Organisation for Economic Co-operation and Development (OECD)/Nuclear Energy Agency (NEA) efforts in nuclear knowledge management. 
Due to unclear prospective funding situation at this point, a budget for the proposed pilot efforts is not made. However, the tasks are defined to allow piecewise developments that would fit into available funds. 


\section{ACRONYMS}

$\begin{array}{ll}\text { API } & \text { Application Program Interface } \\ \text { CASL } & \text { Consortium for Advanced Simulation of Light Water Reactors } \\ \text { CSEWG } & \text { Cross Section Evaluation Working Group } \\ \text { CSNI } & \text { Committee on the Safety of Nuclear Installations } \\ \text { DOE } & \text { Department of Energy } \\ \text { ERCOFTAC } & \text { European Research Community On Flow, Turbulence And Combustion } \\ \text { ESG } & \text { Earth Systems Grid } \\ \text { GEMS } & \text { Generalized Environment for Modeling Systems } \\ \text { ICSBEP } & \text { International Criticality Safety Benchmark Project } \\ \text { INL } & \text { Idaho National Laboratory } \\ \text { IRPhEP } & \text { International Reactor Physics Experiment Evaluation Project } \\ \text { ISP } & \text { International Standards Problem } \\ \text { LLNL } & \text { Lawrence Livermore National Laboratory } \\ \text { MDE } & \text { Material Data Environment } \\ \text { NAFEMS } & \text { National Agency for Finite Element Methods and Standards } \\ \text { NASA } & \text { National Aeronautics and Space Administration } \\ \text { NDMAS } & \text { NGNP Data, Modeling and Analysis System } \\ \text { NE } & \text { Office of Nuclear Energy } \\ \text { NEA } & \text { Nuclear Energy Agency } \\ \text { NEAMS } & \text { Nuclear Energy Advanced Modeling and Simulation } \\ \text { NE-KAMS } & \text { Nuclear Energy Knowledgebase for Advanced Modeling and Simulation } \\ \text { NEKVAC } & \text { Nuclear Energy Knowledge and Validation Center } \\ \text { NPARC } & \text { National Program for Applications-Oriented Research in CFD } \\ \text { OECD } & \text { The Organisation for Economic Co-operation and Development } \\ \text { ORNL } & \text { Oak Ridge National Laboratory } \\ \text { OSTI } & \text { Office of Scientific and Technical Information } \\ \text { PECOS } & \text { Predictive Engineering and Computational Sciences } \\ \text { PNNL } & \text { Pacific Northwest National Laboratory } \\ \text { QNET-CFD } & \text { QNet-Computational Fluid Dynamics } \\ \text { R\&D } & \text { Research and Development } \\ \text { TREAT } & \text { Transient Reactor Test }\end{array}$


This page is intentionally left blank 


\section{BACKGROUND DESCTIPTION}

The Nuclear Energy Knowledge and Validation Center (NEKVAC) is a new initiative by the Department of Energy (DOE) for promoting and supporting nuclear knowledge management and computational simulation code validation. In recent years, computational simulation has been witnessing an increasing and irreplaceable role where physical testing of nuclear systems has become cost and/or time prohibitive. However, to establish trust in the simulation results, evidence must be systematically collected to validate the computational code for the intended applications. As a new frontier, the code validation encounters significant technical and managerial challenges that would require long-term commitment to research and development (R\&D). After several years of brainstorming and preparation, the NEKVAC was initiated to address these challenges with its principal mission consists of the following three major objectives [1]:

1. Identification and prioritization of projects that extend the field of validation science and its application to modern codes;

2. Adapt or develop best practices and guidelines for high fidelity multiphysics/multiscale analysis code development and associated experiment design;

3. Define protocols for data acquisition and knowledge preservation and provide a portal for access to databases currently scattered among numerous organizations.

To effectively achieve these objectives, NEKVAC must heavily leverage existing domestic and international resources and coordinate efforts of industries, universities, and governments in establishing benchmarks and best practices; designing and conducting experiments; and accumulating and managing data and knowledge to advance techniques and methodologies for validation of computational simulation codes. During brainstorming and preparation for NEKVAC initiation, it was concluded that a tangible framework in the form of a knowledgebase system, presumably named the Nuclear Energy

Knowledgebase for Advanced Modeling and Simulation (NE-KAMS), must be created to provide the needed infrastructure with advanced functionalities and tools that supports the desired resource networking, effort coordination, and code validation development. Preparations for the creation of NEKAMS were completed by a team led by the Idaho National Laboratory (INL) in early 2012. Sponsored by the Nuclear Energy Advanced Modeling and Simulation (NEAMS) Program, the team surveyed more than a dozen of existing database systems nationwide and completed a comprehensive assessment on their adequacy for NE-KAMS creation [2]. The Gen IV Materials Handbook System at the Oak Ridge National Laboratory (ORNL) was eventually identified to closely meet the needs and requirements. A NE-KAMS demo was soon created using the infrastructure of the Gen IV Materials Handbook System and successfully demonstrated to DOE Office of Nuclear Energy (NE) at the Germantown headquarters with satisfaction in October 2012. After the official initiation of NEKVAC, a comprehensive implementation plan was developed in 2015 to provide a roadmap for NE-KAMS evolution in support of NEKVAC operations [3]. In the implementation plan, NE-KAMS is redefined with two portals based on its preliminary demo structure and functionalities, i.e. a Resources Portal with the major function of networking to existing databases and expertise, and a Validation Portal with the major function of validation technical development. To prepare technical development for NEKVAC operation and initiate the NE-KAMS implantation plan, meetings were held between NE-KAMS technical lead and NEAMS staff at INL to develop requirements of, and formulate a structure for, a transient fuel database through leveraging adequate existing resources for a pilot project in FY2017. The present plan is created for this pilot project based on discussions and consensus of these meetings. 


\section{SITUATION ANALYSIS}

The imperativeness of developing reliable methodologies and tools for validation of computational simulation codes are well understood in the nuclear energy community. However, approaches to the development and techniques and methodologies of code validation are still largely contentious topics that require extensive discussions and researches. Despite the dispute, it is commonly agreeable that systematical accumulation of evidence that a given computational code or simulation process is adequate for the intended application provides the foundation that is essential to the validation development. In other words, without systematical collection and management of data and knowledge to prove or disprove the trustworthiness of the computational code, other efforts for code validation would become baseless. It becomes apparent that before any desired R\&Ds for code validation under NEKVAC can be effectively conducted, this essential foundation must first be initiated and developed.

Initiation and development of the foundation must involve three major stakeholders: the modeler, the experimentalist, and the knowledgebase developer. Interactions among these three parties from completely different technical areas often escalate into convoluted situations. Based on experience over the past years in code validation development, the following simplified hypothetical scenario is used to facilitate analyzing such situations, defining problems, and formulating a solution.

To fully validate a computational Code $\mathrm{X}$ for an intended Application $\mathrm{Y}$, the modeler must acquire a validation Data Package $V_{e}$ composed of experimental Datasets $\{A S\},\{I C\},\{N E\}$, and $\{$ UD $\}$, where $V_{e}$ represents experimental data. Unfortunately, more often than not, the following situations are encountered:

1. Dataset $\{\mathrm{AS}\}$ is available but scattered in different places, and interrelationships among the data are not documented but some researchers might still remember them;

2. Dataset $\{\mathrm{IC}\}$ is incomplete, lacking information for some parameters;

3. Dataset $\{\mathrm{NE}\}$ does not exist;

4. Dataset $\{\mathrm{UD}\}$ is difficult, if not impossible, to generate because the experimentalist reports that some measurements requested by the modeler are not realistic and others are unclearly defined.

It should be pointed out that some of these situations may overlap. Both the modeler and experimentalist now realize that the requirements for validation data should be developed with all details clearly defined along with the modeling and simulation planning so that the desired data and data interrelationships can be adequately generated and preserved in a knowledgebase system for convenient retrieval and use. However, the knowledgebase developer finds that without even knowing the detail structure of Datasets $\{\mathrm{AS}\},\{\mathrm{IC}\},\{\mathrm{NE}\}$, and $\{\mathrm{UD}\}$ that does not yet exist in its entirety, it is difficult to create a knowledgebase schema that can effectively capture, preserve, and manage the data and, particularly, the interrelationships among the data.

The above scenario has been encountered in the past partially or entirely time and again. It is apparent that a serious disconnection exists in communication among the three parties. The experimentalist is often not sure in advance exactly what data the modeler will need for validation. The modeler often does not know what data already exist, and where and how complete the existing data is, and what can and cannot be realistically measured in experiments. The knowledgebase developer often does not understand what the data structure is for the intended information domain. In summary, no party knows all the details and it is very difficult for them to effectively communicate without a common vision of the entire picture. 
The above analysis suggests that a vehicle must be created to provide a common vision of the whole picture and facilitate communication among the three parties so that they can develop a mutual understanding of each other's needs and requirements. Ideally, a data package that is representative of the data structure and interrelationships among the data for the information domain of interest can provide such a vehicle. From such a representative data package, the molder can clearly specify what information is pertinent to validation of a particular code application; the experimentalist can tell what datasets and data interrelationships are needed and do or do not exist for the intended validation, and the knowledgebase developer can understand what schema is required for preservation and management of the data datasets for the information domain of interest. With such understanding, the rest of the needed communication can be successfully carried out.

Unfortunately, in reality it has been learned time and again that such an ideal representative data package does not exist. As Dinh pointed out in a report summarizing discussions from the Validation Data Working Group Members of the Consortium for Advanced Simulation of Light Water Reactors (CASL), validation data is often found to be from sparse to nonexistent [4]. Although there seem to be considerable amount of existing data scattered in many laboratories, they are often found to be incomplete, lack of pedigree, and not representative of the data structure for the information domain.

To provide the essential foundation for validation development, a representative data package for an information domain of interest to the modeler, the experimentalist, and the knowledgebase developer must first be produced before other activities can be effectively conducted. Because generation of an experimental data package representative of the data structure and data interrelationships for any given information domain of interest to nuclear energy modeling and simulation requires considerable resources and time, an innovative approach must be found to meet the requirements in a time- and cost-effective manner. 


\section{APPROACH AND TASKS}

\subsection{DISCUSSION OF THE APPROACH}

It has become clear from the discussions with NEAMS staff at INL and the analysis result that the major function of the ideal representative data package is to facilitate development of a mutual understanding among the modeler, the experimentalist, and the knowledgebase developer, of the data structure and data interrelationships for an information domain of interest so that all the needs and requirements for and from the three parties can be effectively communicated in validation planning, experiment designing, and knowledgebase development. Therefore, the data package does not have to be completely real experimental data as long as it can provide the desired major function. In fact, there are many existing experimental data packages generated in past R\&D programs sponsored by DOE that are desirable for code validation use but are unfortunately incomplete to be considered representative of the data structure and data interrelationships for its entire information domain. As a solution for the present pilot project, an existing experimental data package can first be selected and then mended with dummy data that fill all the identified gaps to generate a hybrid data package, i.e. Data Package $V_{h}$ that is representative of the data structure and data interrelationships for its information domain, where $\mathrm{V}_{\mathrm{h}}$ indicates hybrid validation data.

In the process to create Data Package $\mathrm{V}_{\mathrm{h}}$, the modeler can clearly identify and document any data interrelationships in Dataset $\{\mathrm{AS}\}$ that are required for intended validation, and any parameters that miss information in Dataset $\{$ IC $\}$ and therefore must be filled with dummy data to completely delineate the structure of the desired dataset; the modeler and the experimentalist can then work together to construct the desired but nonexistent Dataset $\{\mathrm{NE}\}$ with dummy data that reflects the structure and interrelationships of the desired data; they can also discuss to reconcile the desired and realistic measurements and clarify ambiguous definitions of information elements. The knowledgebase developer can learn the data structure from the conversation and develop an understanding of the structural and functional requirements for preservation and management of the information. This process will enable the modeler, the experimentalist, and the knowledgebase developer to discuss without ambiguity what datasets will need to be generated, how to generate them, what measurements will be practical and viable, what knowledgebase schema must be created to capture and preserve the data and data interrelationships, along with all the details that would otherwise be very difficult, if not completely impossible, to envision and communicate.

Once this process is successfully completed, the resulting hybrid Data Package $\mathrm{V}_{\mathrm{h}}$ can be reasonably perceived as a representative instance that could have been generated from a knowledgebase schema required to capture and preserve the data and data interrelationships for validation development of the intended Application Y. Subsequently, the knowledgebase schema can be designed based on the instance with additional considerations for efficient knowledge management. The design will then be used to construct the desired knowledgebase schema. The constructed knowledgebase schema will provide a complete home for Data Package $\mathrm{V}_{\mathrm{h}}$, and more importantly it can generate a data package template that maps out all the attributes and data interrelationships required for data collections for any given validation projects with intended applications similar to Application Y. Because the template will be composed of empty attributes and interrelationship links to be filled with desired data for the validation project, the modelers, the experimentalist, and the knowledgebase developers can conveniently use it for validation planning and management activities. With visual guideline of the template, existing datasets can first be acquired and uploaded into the template, and desired but nonexistent data can be easily identified from the still empty attributes for experimental generation and then uploaded to fill the gaps. A complete validation Data Package $V_{e}$ composed of experimental data can thus be produced in a well-planned, efficiently organized and systematical manner. Furthermore, data that will need massive transfer in and out of the computational code for simulation processing can be specified for digital record creation in 
association with application program interface (API) development to enable automated data exchange between the knowledgebase and the computational code, thus significantly increase simulation and validation efficiency.

In discussion of this approach, considerations must also be given to generating immediate stimulus to some near-future validation development activities of the NEAMS Program as well as long-lasting benefits for the NEKVAC operation. The TREAT Experiments Database has thus been selected to provide the existing experimental data as the core piece for developing the hybrid Data Package $\mathrm{V}_{\mathrm{h}}$. The TREAT Experiments Database contains data generated from hundreds of experiments conducted in the Transient Reactor Test (TREAT) facility during the 35-year period from 1959 to 1994 [5]. The experiments in TREAT were performed to support the development of numerous types of nuclear reactors. Specifically, the experiments investigated the response of various nuclear fuels and fuel element designs to off-normal and accident-related transients, with and without the presence of coolants. The responses ranged from minor fuel damage to gross fuel meltdown. Many of the TREAT experimental datasets are of great interest to validation of computational codes under the NEAMS Program and can thus generate immediate stimulus to some near-future validation development activities for the program.

With existing experimental data of the TREAT Experiments Database as the core piece, Datasets $\{\mathrm{AS}\},\{\mathrm{IC}\},\{\mathrm{NE}\}$, and $\{\mathrm{UD}\}$ as described in the situation analysis will be identified. Data gaps will be filled either with existing data from other sources if available or with dummy data fabricated by subject matter expert modelers of the NEAMS staff at INL to create the desired hybrid Data Package $\mathrm{V}_{\mathrm{h}}$ representative of the data structure and interrelationships for the nuclear reactor transient fuel information domain. All the databases listed below that were previously surveyed by the INL-led team for NEKAMS creation may be considered for networking through NE-KAMS to provide and/or preserve gapfilling experimental data if cost- and time-efficiency can be achieved.

- Earth Systems Grid (ESG) climate modeling database at the Lawrence Livermore National Laboratory (LLNL)

- $\quad$ ENDF/B database from the Cross Section Evaluation Working Group (CSEWG)

- Environmental Management groundwater and soil databases at the Pacific Northwest National Laboratory (PNNL)

- European Research Community On Flow, Turbulence And Combustion (ERCOFTAC) database

- Gen IV Materials Handbook database at the ORNL

- Generalized Environment for Modeling Systems (GEMS) from the INL

- International Criticality Safety Benchmark Project (ICSBEP) database

- International Reactor Physics Experiment Evaluation Project (IRPhEP) database

- International Standards Problem (ISP) database from the Nuclear Energy Agency, Committee on the Safety of Nuclear Installations (CSNI)

- Material Data Environment (MDE) database at Cornell University

- NASA Aero-acoustic V\&V database

- National Agency for Finite Element Methods and Standards (NAFEMS) benchmark database

- NGNP Data, Modeling and Analysis System (NDMAS) database at INL

- NPARC Alliance database 
- Office of Scientific and Technical Information (OSTI) knowledgebase

- Predictive Engineering and Computational Sciences (PECOS) knowledge base at the University of Texas at Austin

- QNET-CFD knowledge base

- Thermal Properties database from thermalhub.org (NSF-funded)

- VELO: A Collaborative Knowledge Management Framework for Simulation and Modeling from the PNNL

\subsection{DEFINITION OF TASKS}

To develop requirements of, and formulate a structure for, a transient fuel database using the TREAT Experiments Database as the major existing experimental data source, the following tasks are proposed:

Task 1: Select Application $\mathrm{Y}$ and its simulation Code $\mathrm{X}$ for validation

The following criteria listed in descending priority order will be considered in the selection:

1) Representativeness of the application for transient fuel phenomena;

2) Completeness likelihood of validation data that can be found in the TREAT Experimental Database;

3) Popularity of the simulation code.

As Application $\mathrm{Y}$ and Code $\mathrm{X}$ are selected, the validation data will be identified in considering criterion 2).

Deliverable: A PowerPoint presentation on the identified Application Y and Code X

\section{Task 2: Create an inventory of the identified TREAT validation data}

The identified TREAT validation data will provide core elements for developing requirements of, and formulating a structure for, a transient fuel database. The identified data should inherit representativeness for the fuel transient information domain from that of the selected Application Y. The inventory must include the following information:

1) Dataset Filename;

2) Dataset Description;

3) Dataset Information Type, e.g. report, equipment, material property etc.;

4) Dataset File Type/Extension, e.g. jpg, pdf, avi, txt, vi, xlsm etc.;

5) Dataset File Size.

Deliverable: An inventory of identified TREAT validation data in spreadsheet.

\section{Task 3: Create a data inventory for hybrid Data Package $V_{h}$}

The needs and requirements for experimental data to validate Code $\mathrm{X}$ for Application $\mathrm{Y}$ will be analyzed to identify all the desired datasets. By comparison with the TREAT validation data inventory, Datasets $\{A S\},\{I C\},\{N E\}$, and $\{\mathrm{UD}\}$ that would compose the ideal validation Data Package $\mathrm{V}_{\mathrm{e}}$ will be 
identified. All the missing elements will be filled in with experimental data from other existing sources (if available) or fabricated dummy data (if nonexistent) to create an inventory for hybrid Data Package $\mathrm{V}_{\mathrm{h}}$ as an instance of the ideal validation data that is desired to validate Code $\mathrm{X}$ for Application $\mathrm{Y}$. The dummy data should imitate the information type, structure, and interrelationships of the desired data that are nonexistent. The inventory will include the following information wherever applicable:

1) Dataset Filename;

2) Dataset Description;

3) Dataset Information Type, e.g. report, equipment, material property etc.;

4) Dataset File Type/Extension, e.g. jpg, pdf, avi, txt, vi, xlsm etc.;

5) Dataset File Size.

Deliverable: A data inventory for hybrid Data Package $V_{h}$ representative of the ideal validation data for Code X and Application Y in spreadsheet.

\section{Task 4: Define structure of a hypothetical ideal validation Data Package $\mathbf{V}_{h}$}

Two steps will be taken to define the main structure and the fine structure, respectively. To define the main structure, all data in the hybrid data inventory will be categorized by their information types, e.g. report, equipment, material property, fluid property, test result, reference, and so on. To further define the fine structure, each information category will be individually analyzed to group its information elements. Take the category of equipment as an example, information in the equipment datasets may be organized in groups of Structure and Geometry, Invasive Instrument, Non-invasive Instrument, Data Acquisition System, Test Control System, Experiment Operation, and so on. Each group contains attributes for a set of information elements with close association, e.g. the Structure and Geometry group may contain attributes of Test Equipment Design Document, Test Equipment Design Drawing, Experiment Equipment Photo, Wetted Surface Document, and so on.

Deliverable: A set of spreadsheet files each for an information category with organized groups of attributes for closely associated information elements.

\section{Task 5: Formulate the structure for transient fuel database}

The deliverable of Task 4 will be analyzed to provide the basis for formulating the transient fuel database structure. Based on the analysis, the complete structure for transient fuel database will be formulated through the following steps:

1) Delineate the transient fuel database schema based on the deliverable of Task 4; each category spreadsheet will be used to define a database table.

2) Identify interrelationships among categories, groups, and attributes; design database links that maintain the identified interrelationship to ensure pedigree traceability and data integrity.

3) Identify search needs from the perspectives of modelers and experimentalists; define search criteria and design search attributes and search mechanisms.

4) Identify access control needs and requirements; define access control user groups and design access control schemas.

5) Identify data contribution and management needs and requirements; define data contribution and management attributes.

6) Identify data quality assessment needs and requirements; define quality assessment management attributes. 
7) Identify data quality assurance needs and requirements; define quality assurance management attributes.

8) Identify information sensitivity management needs and requirements; define information sensitivity categories.

9) Identify terminology definition needs and requirements; define terminology attributes and online help menu mechanisms.

10) Identify data that requires massive and automated transfer between Code $X$ and the knowledgebase; define data transfer requirements and digital record layouts.

Deliverable: A set of spreadsheet files that describes in details the structure for transient fuel database. These files will provide a blueprint of database schema design for construction of the database structure.

\section{Task 6: Evaluate the design of the formulated transient fuel database structure}

The inventory of hybrid data created in Task 3 will be used to evaluate the formulated transient fuel database structure design. The inventory will be reformatted into the database schema design to evaluate its accommodation capacity. Modifications will be made as needed to refine the structure design.

Deliverable: A set of spreadsheet files that contains the hybrid Data Package $V_{h}$ inventory along with all the additional attributes and link requirements from Task 5 accommodated in the transient fuel database structure.

\section{Task 7: Evaluate operability of the formulated transient fuel database structure}

Operability of the formulated transient fuel database structure will be evaluated through the following steps:

1) Select existing databases to be considered for networking to provide and/or preserve gap-filling experimental data as discussed in Section 3.1.

2) Modify NE-KAMS Validation Portal structure to cover all the structural holes found in the selected databases to meet the structural requirements identified from the deliverable of Task 6.

3) Upload the hybrid Data Package $\mathrm{V}_{\mathrm{h}}$ into the transient fuel database structure in NE-KAMS for accommodation capability and operability testing; make modifications to satisfaction.

4) Create networking links in NE-KAMS Resource Portal to connect the databases selected in Step 1) to complementarily provide existing experimental data for composing validation Data Package $\mathrm{V}_{\mathrm{e}}$.

Selection of existing databases in Step 1) should be determined by factors of cost and time efficiency, such as the applicable data already preserved, structural suitability, and convenience for uploading gapfilling new data. The selected databases after networking will allow new experimental data to be generated and preserved in at different locations, e.g. NDMAS at INL or VELO at PNNL.

Deliverable: An evaluation report on structural and functional capabilities of the formulated transient fuel database structure with suggestions for a plan to create validation Data Package $V_{\mathrm{e}}$.

Due to unclear prospective funding situation at this point, a budget is not made. However, these tasks are defined to allow piecewise developments that would fit into available funds. Duration of each task is dependent on the available budget. 


\section{FUTURE PLANNING}

With the transient fuel database requirements developed and structure formulated along with all existing data identified and networked, future plans for development can be confidently made.

For generation of new experimental data that fill the data gaps found in the existing data preserved in the networked databases, testing plans can be effectively made with a clear vision using the tangible map of the data structure for the transient fuel information domain provided by the hybrid Data Package $\mathrm{V}_{\mathrm{h}}$ uploaded in NE-KAMS.

For validation technique and methodology development, desirable activities can be carried out in trials using the hybrid Data Package $\mathrm{V}_{\mathrm{h}}$ preserved in NE-KAMS to test viability until an optimal validation plan is formulated and detail requirements for generating real experimental data are defined.

For validation data that need massive and automated transfer in and out of the computational code for simulation processing, the required digital records and API can be developed using the hybrid Data Package $\mathrm{V}_{\mathrm{h}}$ in NE-KAMS as a template for design and operational trials.

For development of collaboration with and support to OECD and NEA effort in nuclear knowledge management, networking to existing databases and knowledgebases can be established based on the experience gained through this pilot project. 


\section{REFERENCES}

1. "Nuclear Energy Knowledge and Validation Center - TREAT Pilot Project Support from Oak Ridge National Laboratory," Document ID: SOW-13440, Revision ID: 0, INL/MIS-16-39773, August 31, 2016, Idaho National Laboratory.

2. "A Survey of Existing V\&V, UQ and M\&S Data and Knowledge Bases in Support of the Nuclear Energy - Knowledge base for Advanced Modeling and Simulation," Department of Energy Nuclear Energy Advanced Modeling and Simulation (NEAMS) Program, March 2012, Hyung B. Lee and Kimberlyn C. Mousseau..

3. "Nuclear Energy Knowledgebase and Simulation Code Validation System Development and Implementation Plan," ORNL/TM-2015/420, August 30, 2015, Weiju Ren and Tim Valentine.

4. "Validation Data Needs Survey," the Consortium for Advanced Simulation of Light Water Reactors, Department of Energy, L2:VUQ.P7.01, CASL-I-2013-0194-000, September 29, 2013, Nam Dinh.

5. “TREXR: The TREAT Experiments Database," ANL-ARC-257, Nuclear Engineering Division, Argonne National Laboratory, May 31, 2013, A. E. Wright, P. H. Froehle, and T. Sofu. 
ORNL/TM-2016/615

\section{DISTRIBUTION LIST}

\section{INTERNAL DISTRIBUTION}

\begin{tabular}{|l|l|l|l|l|l|}
\hline J. T. & Busby & busbyjt@ornl.gov & C. V. & Parks & parkscv@ ornl.gov \\
\hline J. C. & Gehin & gehinjc @ornl.gov & W. D. & Pointer & pointerwd@ ornl.gov \\
\hline D. E. & Holcomb & holcombde @ ornl.gov & B. T. & Rearden & reardenb @ ornl.gov \\
\hline D. B. & Kothe & kothe @ ornl.gov & W. & Ren & renw @ ornl.gov \\
\hline E. & Lara-Curzio & laracurzioe@ ornl.gov & P. F. & Tortorelli & tortorellipf@ ornl.gov \\
\hline L. & Lin & linl@ ornl.gov & T. E. & Valentine & valentinete @ ornl.gov \\
\hline G. T. & Mays & maysgt @ ornl.gov & & & \\
\hline
\end{tabular}

\section{EXTERNAL DISTRIBUTION}

\begin{tabular}{|l|l|l|l|}
\hline S. & Bajorek & stephen.bajorek@ nrc.gov & Nuclear Regulatory Commission \\
\hline W. R. & Corwin & William.Corwin@ Nuclear.Energy.Gov & Department of Energy \\
\hline N. & Dinh & ntdinh@ncsu.edu & North Carolina State University \\
\hline P. J. & Finck & phillip.finck@inl.gov & Idaho National Laboratory \\
\hline C. P. & Folsom & charles.folsom@inl.gov & Idaho National Laboratory \\
\hline D. & Funk & DAN.FUNK@ @uclear.energy.gov & Department of Energy \\
\hline G. W. & Griffith & George.Griffith@inl.gov & Idaho National Laboratory \\
\hline H. D. & Gougar & hans.gougar@inl.gov & Idaho National Laboratory \\
\hline J. D. & Hales & jason.hales@inl.gov & Idaho National Laboratory \\
\hline K. & Ivanov & kni1@engr.psu.edu & Pennsylvania State University \\
\hline H. S. & Khalil & hkhalil@anl.gov & Argonne National Laboratory \\
\hline H. & Lee & hyung.lee@ unnpp.gov & Bettis Atomic Power Laboratory \\
\hline V. A. & Mousseau & vamouss@ sandia.gov & Sandia National Laboratory \\
\hline W. & Oberkampf & wloconsulting@gmail.com & Consultant \\
\hline T. & O'Connor & Tom.Oconnor@Nuclear.Energy.gov & Department of Energy \\
\hline C. & Rabiti & cristian.rabiti@inl.gov & Idaho National Laboratory \\
\hline R. & Richard & Richard.Wright@inl.gov & Idaho National Laboratory \\
\hline U. S. & Rohatgi & rohatgi@bnl.gov & Brookhaven National Laboratory \\
\hline S. & Sham & ssham@anl.gov & Argonne National Laboratory \\
\hline P. & Sharpe & phil.sharpe@inl.gov & Idaho National Laboratory \\
\hline B. & Singh & BHUPINDER.SINGH@ nuclear.energy.gov & Department of Energy \\
\hline C. J. & Sink & carl.sink@nuclear.energy.gov & Department of Energy \\
\hline D. M. & Wachs & daniel.wachs@inl.gov & Idaho National Laboratory \\
\hline J. C. & Wagner & john.wagner@inl.gov & Idaho National Laboratory \\
\hline & & & \\
\hline
\end{tabular}

